\title{
Your Experience is Important! The User Experience Questionnaire (UEQ) - Estonian Version
}

\author{
Jana Kadastik ${ }^{1}$ MA; Tiia Artla ${ }^{2}$ MA; Martin Schrepp ${ }^{3} \mathrm{PhD}$ \\ Tallinn University, Estonia ${ }^{1,2}$, SAP SE, Germany ${ }^{3}$ \\ janajana@tlu.ee ${ }^{1}$; tiiartla@tlu.ee ${ }^{2}$; martin.schrepp@ sap.com $^{2}$
}

\begin{abstract}
The User Experience Questionnaire (UEQ) is a measuring instrument for evaluating subjective experience of the users of interactive products. The study set out to adapt the UEQ to the Estonian language and to use it for evaluating everyday objects (learning tools), i.e. to test if the UEQ can be used also for a class of objects that were not in the scope of the construction of the UEQ. The data analysis is based on the instrument developed by the creators of the UEQ: UEQ Data Analysis Tool. It can be concluded from the study that the adaptation of the UEQ to the Estonian language was successful as the measurable values were mostly within the permissible range. Although the scale Dependability has a smaller consistency value, it is not small enough to indicate a significant problem. The study demonstrated that it is possible to use an instrument originally designed to assess interactive products for assessing non-interactive products. Thus, the questionnaire is presumably applicable to assess a range of varied products.
\end{abstract}

Keywords: user experience; measurement; user-centred design; student-centred learning; questionnaire; special education.

\section{Introduction}

In education, as well as in designing everyday objects, more and more attention is paid to the learner/user experiencing positive emotions. For example, in a recent interview J. Groccia admitted that the emotional side in learning is very important and the learner is able to much better concentrate on learning when feeling secure (Merisalu, 2015). When the focus of the design changes from a "well-fare" to a "well-being" society, the possibility of designing for happiness may also arise (Hassenzahl et al., 2013).

Today there is a movement towards an inclusive environment, where increasingly more importance is attached to the need to create products and services that would correspond to the needs of different target groups. The authors of this paper focus on education, more specifically on special pedagogy. In the interests of society as a whole, it is completely natural to expect that all children receive education that meets their physical and mental abilities, needs and possibilities. Therefore, learners' needs should be taken into account when developing learning tools and environments. Research on infants' toys has found that only $5 \%$ of the toys analysed are actually accessible for children with hearing, motor and visual impairment and did not require any adaptation or help to be played (Perino, 2017). A study conducted in Estonia shows that to teach children with severe and profound intellectual disabilities and multiple disabilities mainly learning tools produced by teachers themselves and musical instruments are used. However, it has to be stated that the selected infants' toys and learning tools made by teachers often do not take into consideration the special needs arising from the cognitive processes of students. When designing for people with abilities and needs that differ much from the designer's own experience, it is important to use user-centred design techniques. When working with people with a mental impairment, this may be even more important, because the nature, capabilities, limitations and behaviour of the individuals belonging to this target group are very diverse (Hosea, Vermeeren, 2009). Thus, in order to develop aids that meet students' (children's) needs, user feedback should be requested during the whole designing process. Different people understand, the term user experience, in very different ways (All About UX, 2017).

In this paper, we rely on the definition by M. Hassenzahl (2008): "UX is a momentary, primarily evaluative feeling (good-bad) while interacting with a product or service. By that, UX shifts attention from the product and materials (i.e., content, function, presentation, interaction) to humans and feelings - the subjective side of product use." Therefore, user experience is a summary of the findings: fun of use, aesthetics, emotions, stimulation or attractiveness (Cota et al., 2014). The best opportunity would be to ask feedback from the users, i.e. children (primary users) themselves. Unfortunately, collecting opinions from children with special needs or infants is complicated, as they either cannot answer or due to their 
special need are not able to answer. Since most frequently teachers are the ones who, based on their earlier experience of work with children with special needs, choose which teaching aids to use, one way is to ask the teachers (secondary users) to give feedback on the applicability of a teaching aid and compare the outcome to the responses received from students. Naturally, it has to be taken into account that in that case the notions of the secondary users are not necessarily correct or in keeping with the opinions of primary users (Hosea, Vermeeren, 2009). People who design and develop these tools have to address the needs of secondary users and build them in the design and evaluation process of the system. It may mean that conflicting needs between primary and secondary users need to be dealt with (Alsos, Svanæs, 2011).

It is important that the implementation of an instrument of measuring user experience would allow fast and simple assessment of a teaching aid in different stages of its development. Considering the above, the authors found that the User Experience Questionnaire (UEQ) that is available free of charge (the questionnaire itself and all material required for data analysis and data interpretation can be downloaded in several languages from www.ueq-online.org) could offer a quick opportunity for comprehensive assessment of user experience.

\section{User Experience Questionnaire}

The User Experience Questionnaire (UEQ) provides an opportunity to quickly assess the experience of the users of interactive products. The questionnaire is designed in a format that allows users to instantly express the feelings, impressions and attitudes that they experience when using a product. The scales of the UEQ cover a wide range of user experience, measuring classical usability aspects (efficiency, perspicuity, dependability) as well as user experience aspects (originality, stimulation) (User Experience Questionnaire, 2017). The original version of the UEQ was created in the German language in 2006 (Laugwitz, Schrepp, Held, 2006). A handbook (Schrepp, 2017) describes the handling an interpretation of the results. In its current form, the UEQ can be easily applied, offering an opportunity for reliable and valid measurement of user experience, and the received data can complement the data obtained by other evaluation methods that have subjective quality ratings (Laugwitz, Held, Schrepp, 2008).

The 6 scales of the UEQ contain 26 items as follows (Schrepp, Hinderks, Thomaschewski, 2017b).

- Attractiveness: General impression of the product. Is it liked or disliked by users? Do they perceive it as attractive, enjoyable or pleasing?

6 items: annoying / enjoyable, good / bad, unlikable / pleasing, unpleasant / pleasant, attractive / unattractive, friendly / unfriendly.

- Perspicuity: How easy is it to get to know the product? Can it be easily learnt and understood? Is it clear?

4 items: not understandable / understandable, easy to learn / difficult to learn, complicated / easy, clear / confusing.

- Efficiency: Do users have to make an effort to solve their tasks? How efficient and fast is the interaction? How immediate is the product's response to user input?

4 items: fast / slow, inefficient / efficient, impractical / practical, organized / cluttered.

- Dependability: Does the interaction allow the user to feel in control? Can the system's behaviour be predicted? Does working with the product make the user feel safe?

4 items: unpredictable / predictable, obstructive / supportive, secure / not secure, meets expectations / does not meet expectations.

- Stimulation: How exciting and motivating is it to use the product? Does the user have fun? 4 items: valuable / inferior, boring / exciting, not interesting / interesting, motivating / demotivating.

- Novelty: Is the product innovative and creative? Is the users' attention captured? 4 items: creative / dull, inventive / conventional, usual / leading-edge, conservative / innovative.

Attractiveness belongs to the dimension of pure valence. Perspicuity, Efficiency and Dependability represent pragmatic quality (which is goal-directed) and Stimulation and Novelty appear as representatives of hedonic quality (and are not goal-directed) (Schrepp, 2017). It is not assumed that the scales are independent (Figure 1). The general assumption is that the evaluation of the Attractiveness is based on the impression towards the other 5 scales, i.e. that the attractiveness is a result of the perceived perspicuity, efficiency, dependability, stimulation and novelty (Schrepp, Hinderks, Thomaschewski, 2017b). 


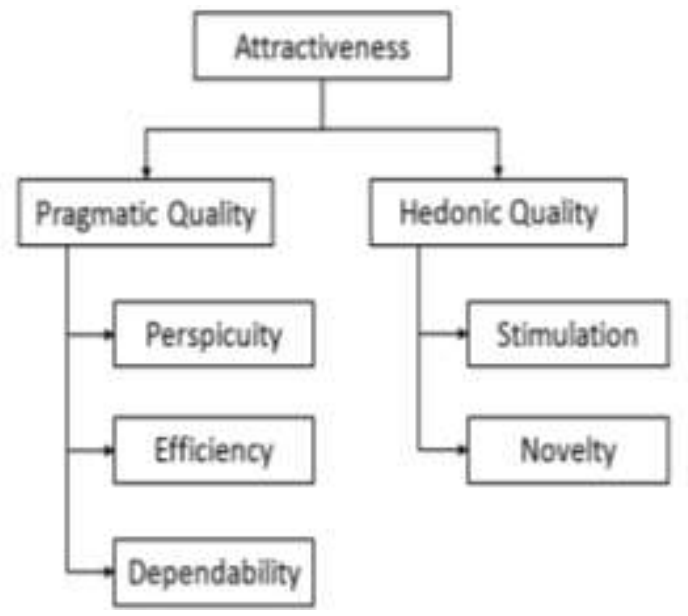

Figure 1. Assumed scale structure of the UEQ (Schrepp, Hinderks, Thomaschewski, 2017b).

\begin{tabular}{|c|c|c|c|c|c|c|c|c|c|}
\hline & 1 & 2 & 3 & 4 & 5 & 6 & 7 & & \\
\hline annoying & 0 & 0 & 0 & 0 & 0 & 0 & 0 & enjoyable & 1 \\
\hline not understandable & 0 & 0 & 0 & 0 & 0 & 0 & 0 & understandable & 2 \\
\hline creative & 0 & 0 & 0 & 0 & 0 & 0 & 0 & dull & 3 \\
\hline easy to learn & 0 & 0 & 0 & 0 & 0 & 0 & 0 & difficult to learn & 4 \\
\hline valuable & 0 & 0 & 0 & 0 & 0 & 0 & 0 & inferior & 5 \\
\hline boring & 0 & 0 & 0 & 0 & 0 & 0 & 0 & exciting & 6 \\
\hline not interesting & 0 & 0 & 0 & 0 & 0 & 0 & 0 & interesting & 7 \\
\hline unpredictable & 0 & 0 & 0 & 0 & 0 & 0 & 0 & predictable & 8 \\
\hline fast & 0 & 0 & 0 & 0 & 0 & 0 & 0 & slow & 9 \\
\hline inventive & 0 & 0 & 0 & 0 & 0 & 0 & 0 & conventional & 10 \\
\hline obstructive & 0 & 0 & 0 & 0 & 0 & 0 & 0 & supportive & 11 \\
\hline good & 0 & 0 & 0 & 0 & 0 & 0 & 0 & bad & 12 \\
\hline complicated & 0 & 0 & 0 & 0 & 0 & 0 & 0 & easy & 13 \\
\hline unlikable & 0 & 0 & 0 & 0 & 0 & 0 & 0 & pleasing & 14 \\
\hline usual & 0 & 0 & 0 & 0 & 0 & 0 & 0 & leading edge & 15 \\
\hline unpleasant & 0 & 0 & 0 & 0 & 0 & 0 & 0 & pleasant & 16 \\
\hline secure & 0 & 0 & 0 & 0 & 0 & 0 & 0 & not secure & 17 \\
\hline motivating & 0 & 0 & 0 & 0 & 0 & 0 & 0 & demotivating & 18 \\
\hline meets expectations & 0 & 0 & 0 & 0 & 0 & 0 & 0 & $\begin{array}{l}\text { does not meet } \\
\text { expectations }\end{array}$ & 19 \\
\hline inefficient & 0 & 0 & 0 & 0 & 0 & 0 & 0 & efficient & 20 \\
\hline clear & 0 & 0 & 0 & 0 & 0 & 0 & 0 & confusing & 21 \\
\hline impractical & 0 & 0 & 0 & 0 & 0 & 0 & 0 & practical & 22 \\
\hline organized & 0 & 0 & 0 & 0 & 0 & 0 & 0 & cluttered & 23 \\
\hline attractive & 0 & 0 & 0 & 0 & 0 & 0 & 0 & unattractive & 24 \\
\hline friendly & 0 & 0 & 0 & 0 & 0 & 0 & 0 & unfriendly & 25 \\
\hline conservative & 0 & 0 & 0 & 0 & 0 & 0 & 0 & innovative & 26 \\
\hline
\end{tabular}

Figure 2. The English version of the UEQ (Schrepp, Hinderks, Thomaschewski, 2017a).

Applying the UEQ does not require much effort. Usually 3-5 minutes are sufficient for a participant to read the instructions and complete the questionnaire. The UEQ can be used in a paper-pencil form as part of a classical usability test (and this still is the most common application) (Schrepp, Hinderks, Thomaschewski, 2017b). The 26 items of the UEQ are listed in the table below (Figure 2). Each item of the UEQ consists of a pair of terms with opposite meanings. 
Participants rate each item on a 7-point Likert scale. The answers are scaled from -3 (fully agree with negative term) to +3 (fully agree with positive term). Half of the items start with the positive term, the others with the negative term (in randomized order) (Schrepp, Hinderks, Thomaschewski, 2017b).

The UEQ is available in 20 languages. An Excel sheet for data analysis, and the UEQ Handbook are available free of charge at User Experience Questionnaire homepage (http://www.ueq-online.org).

For semantic differentials like the UEQ, it is essential that participants are able to read the items in their mother tongue (Cota et al., 2014). Therefore, it is important to be able to use the questionnaire in the native language in Estonia.

The goal of the article is to translate the UEQ into the Estonian language and check the applicability of the test originally designed to assess interactive products on the assessment of everyday objects (learning tools) and ascertain the reliability of the translated version.

\section{Methodology}

\section{Development of the Estonian Version of the UEQ}

The creators of the UEQ (M. Schrepp and A. Hinderks) were contacted by email to ask their permission to adapt the questionnaire to the Estonian language. The authors gave their permission as well as instructions for conducting the process. The adaptation was carried out according to the received instructions. The original German language version as well as the English language version and translations into several other languages are available on the UEQ homepage. The translation into the Estonian language was based on the German and English language versions. First, it was explained to the translators what the test was intended to measure and how important it was to select appropriate words in the Estonian language. Next, the translators were able to familiarise themselves with the materials on the UEQ webpage. While translating the test into Estonian, an analogy with the translation into Portuguese was followed, as in the process of translating the relation to the original dimension has to be maintained, i.e. the questionnaire has to measure the same qualities, which means that the chosen words need to have a similar meaning to the original words and make respondents experience the same feelings when performing the test independent of the language they use (Cota, Thomaschewski, Schrepp, Goncalves, 2014).

Firstly, professional English-Estonian and German-Estonian translators carried out the translation into Estonian. That was followed by the comparison of the two versions of the translation in Estonian and finding relevant Estonian language synonyms. At the next stage, a professional Estonian language editor checked the Estonian translation. Thereafter, a user experience specialist assessed the vocabulary used in the test to ensure its consistency with the daily used special terminology. Then the Estonian version was translated back into the English and German languages. An outcome of that process was the versions in the original languages (German, English), which were identical with the initial versions. The last step was testing the Estonian language version of UEQ in practice.

\section{Participants and Context of the Study}

The study aimed to focus on the implementation of the UEQ rather than on the assessment of interactive objects or teaching materials, to allow us later to use this questionnaire for assessing teaching aids or learning tools used in special education. It was essential to find participants who would use the same aids or tools over a certain period of time. Fifty-one students of Tallinn University whose minor subject was Learning Support and who were taking the course "Play and Movement as Supportive Activity in Remedial Education" participated in the study. They were all native speakers of Estonian.

As part of the above course the students made a Bean Bag of cotton fabric, weighing $100 \mathrm{~g}$, with measurements $15 \times 11 \mathrm{~cm}$, filled with different material (rice, peas, beans or buckwheat). During the course the students learned how to use the Bean Bags in educational work with children with special needs (fine motor skills exercises, various games and motor activities). At the completion of the course the students assessed their user experience of utilising the Bean Bags by means of the Estonian language version of the UEQ. For that purpose, the participants were first introduced to the questionnaire and the principles of assessing user experience. The students were informed that the participation in the study was voluntary and anonymous. 


\section{Data Collection Procedure}

The Estonian language version of the UEQ was used to measure user experience of special education leaning tools (Bean Bags). The students participating in the study used a version of the UEQ printed on paper, marking their responses on the scales with a pen or pencil. To analyse the received data, we applied the UEQ Data Analysis Tool, which is available free of charge on the UEQ homepage. The goal of this tool is to facilitate the analysis of UEQ data. First, the data obtained from respondents needs to be entered into the Data Worksheet. The tool then calculates all the statistics necessary to interpret the results and automatically creates diagrams (User Experience Questionnaire, 2017).

\section{Results and Discussion}

\section{The First Evaluation of the Estonian Version}

The data analysis was carried out by means of the instrument developed by the creators of the UEQ: UEQ Data Analysis Tool, which is downloadable free of charge from the UEQ homepage. The authors of the instrument have taken into account that UEQ does not produce an overall score for the user experience. Because of the construction of the questionnaire it does not make sense to build such an overall score (for example by calculating the mean over all scales), since this value cannot be interpreted properly.

\section{Detect Suspicious Data}

Not all participants will always answer all items seriously. To detect such more or less random or not serious answers a simple heuristic is used. All items in a scale should measure a similar quality aspect. The idea to detect random or not serious answers is to check how much the best and worst evaluations of an item in a scale differ. If there is a big difference $(>3)$ this is seen as an indicator of a problematic data pattern. Such situations can also result from random response errors or misunderstanding of an item. Thus, it makes no sense to consider a response as problematic if this occurs just for a single scale. But if this is true for 2 or 3 scales, it is of course a clear hint that the response is unreliable (User Experience Questionnaire, 2017).

In our study, response errors or misunderstandings were identified in three respondents out of 51 participants. Two respondents' value of the indicator for a problematic data pattern was " 4 " and that for one respondent was " 5 ". This means that overall the Estonian language version of the UEQ had been understandable and the majority of the respondents had answered seriously.

\section{Cronbach's Alpha coefficient}

Cronbachs Alpha coefficient (Cronbach, 1951) was calculated for each of the sub-scales. The Cronbach's Alpha value are: attractiveness 0.86 ; perspicuity 0.6; efficiency 0.65 ; dependability 0.52 ; stimulation 0.8; novelty 0.76 . Only the scale Dependability has a smaller consistency value. Similar results with Cronbach's Alpha coefficient $<0.7$ were also received for some subscales on the first-time use of the Portuguese and Indonesian language versions (Cota et al., 2014; Santoso et al., 2016). The Indonesian version also assessed learning tools (although digital ones, in an e-Learning Environment) and the Dependability value was lower $(\alpha=0.58)$, which was associated with the less important role of this property for the user experience of a learning platform or with possible problems with the interpretation of the items in this scale (Santoso et al., 2016). The same may be true of the Estonian version and, in addition, it may be an effect of the size of the sample. Regarding the Estonian version, some variation may be due to the learning tool (Bean Bag) chosen for the assessment. Although the scale Dependability has a smaller consistency value, it is not small enough to indicate a significant problem. According to this result, the reliability of the Estonian version of the UEQ is satisfactory.

\section{The Benchmark}

The benchmark graph from the Excel-Tool shows the UX quality of the evaluated product. The benchmark is invaluable in the first-time application of the UEQ to measure a product, i.e. there are no earlier evaluation results available (Schrepp, Hinderks, Thomaschewski, 2017b). The benchmark can be used to compare the results measured with the UEQ to the results of other products (Santoso et al., 2016). Since 
at the present time the benchmark data set only contains a limited number of evaluation results, a decision was taken to limit the feedback to 5 categories per scale (Schrepp, Hinderks, Thomaschewski, 2017a):

- excellent: the product that is evaluated appears among the best $10 \%$ of results;

- good: in the benchmark $10 \%$ of the results are better than the evaluated product and $75 \%$ are worse;

- above average: in the benchmark $25 \%$ of the results are better than the evaluated product and $50 \%$ are worse;

- below average: in the benchmark 50\% of the results are better than the evaluated product and $25 \%$ are worse;

- bad: the evaluated product is among the worst $25 \%$ of the results.

The Figure 3 below illustrates the benchmark of the Bean Bags.

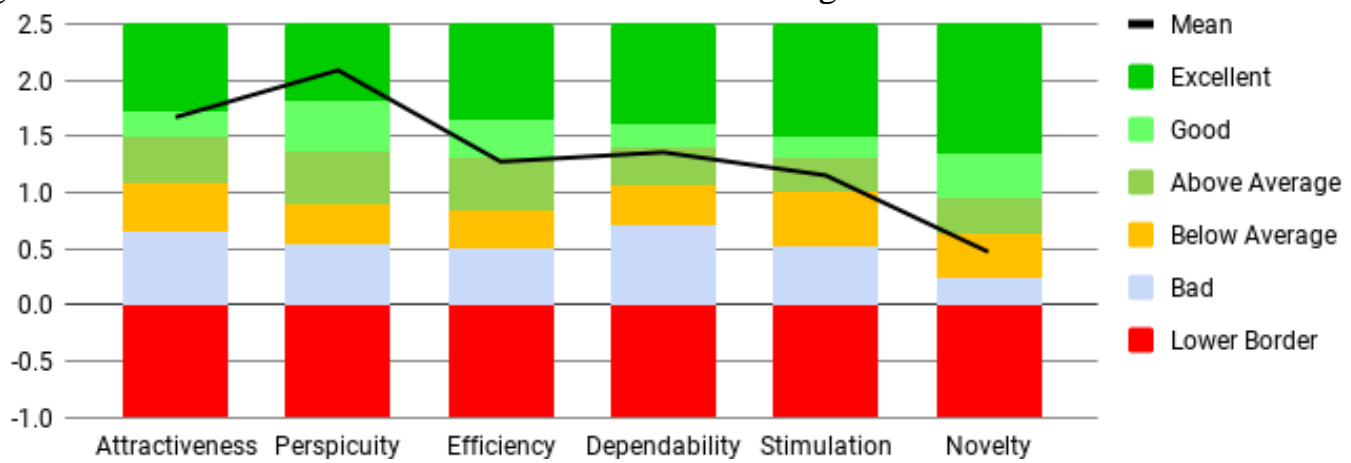

Figure 3. Visualization of the benchmark of Bean Bags.

The line represents the results for the evaluated product. The coloured bars represent the ranges for the scales' mean values.

The creators of the UEQ have taken into account that over time the expectations of the general UX have increased. Given the fact that the benchmark also includes data from the measurements of established products, it is necessary for a new product to achieve the Good standard in all scales (Schrepp, Hinderks, Thomaschewski, 2017b). The results reveal (Figure 3), that the only value that is lower is related to Novelty. This is fully justified, as the Bean Bags were made to match the existing bags that had been used before and students merely learned to use them as tools to support learning. The benchmark can be used to compare the results of a product measured with the UEQ to the results of other products (Santoso et al., 2016). The developers of the UEQ recognise the need to create different benchmarks for different product categories in the future (Schrepp, Hinderks, Thomaschewski, 2017b).

\section{Conclusion}

The task of this study was to adapt the UEQ to the Estonian language and to carry out the initial assessment of user experience. It proved a great challenge to test for the first time if the measuring instrument originally devised to evaluate user experience of interactive products is applicable to assess a non-interactive tool (Bean Bag) used in special needs education. The study allows us to conclude that the adaptation of the UEQ to Estonian was successful, since the measurable values were mostly within the permissible range. Although the scale Dependability has a smaller consistency value, it is not small enough to indicate a significant problem. According to this result, the reliability of the Estonian version of the UEQ is satisfactory.

UEQ allows a quick and easy analysis of user feedback on a product. Our study showed that an instrument originally developed for measuring interactive products could also be used to assess noninteractive objects. This proves that the questionnaire is suitable for evaluating very diverse products. Obviously, in the future when the UEQ is going to be used to assess non-interactive products, it is essential to develop a separate benchmark for that category.

The authors of this article were interested in using the UEQ to evaluate learning tools for special needs education. The UEQ allows, for instance, assessing teachers' user experience and comparing the received data to students' user experience. Unfortunately, the UEQ is not suitable for getting feedback form infants and children with intellectual disabilities (assessment by means of behavioural indicators would be more 
appropriate for them, e.g. eye tracking). Presumably, the implementation of the UEQ could be feasible for basic school students. At the same time, in the studies of infants and children with intellectual disabilities (they could be called primary users) a significant role belongs to parents, carers and teachers as well as various specialists (secondary users), who support the children and the cared for in their daily activities and learning. They may be considered very important sources of background information. The UEQ is a perfect tool for assessing the user experience of secondary users, which allows collecting a wide range of background information. Currently the Estonian language version is available free of charge on the UEQ homepage and for that reason a copy of it has not been attached to the article.

\section{Bibliography}

1. All About UX. (2017). WordPress. Retrieved from http://www.allaboutux.org/

2. Alsos O.A., Svanæs D. (2011). Designing for the secondary user experience. In P. Campos, N. Graham, J. Jorge, N. Nunes, P. Palanque, M. Winckler (Eds.), The Proceedings of the International Conference Human-Computer Interaction - INTERACT 2011, 13. Lisbon, Portugal: INTERACT, 84-91.

3. Cota M.P., Thomaschewski J., Schrepp M., Goncalves R. (2014). Efficient Measurement of the User Experience. A Portuguese Version. (5th International Conference on Software Development and Technologies for Enhancing Accessibility and Fighting Info-exclusion, DSAI 2013). Procedia Computer Science, 27, 491-498.

4. Cronbach L.J. (1951). Coefficient alpha and the internal structure of tests. Psychometrika, 16(3), 297-334. Retrieved from

https://pdfs.semanticscholar.org/e985/ac2e151903000cac310ffbc5b2cb4fbb9dd5.pdf

5. Hassenzahl M. (2008). User experience (UX): Towards an experiential perspective on product quality. In E. Brangier, G. Michel (Eds.), Proceedings of the International Conference of The Association Francophone d'Interaction Homme-Machine, IHM'08, 20, 11-15. Retrieved from

https://www.researchgate.net/publication/238472807 User_experience UX Towards an experiential perspective on product quality

6. Hassenzahl M., Eckoldt K., Diefenbach S., Laschke M., Len E., Joonhwan K. (2013). Designing Moments of Meaning and Pleasure. Experience Design and Happiness. International Journal of Design, 7(3), 21-31.

7. Hosea S.I., Vermeeren A.P.O.S. (2009). Experiences in designing for and with mentally impaired users: the design of a device to structure time and activities. In B. Sapio, L. Haddon, E. Mante-Meijer, L. Fortunaki, T. Turk, E. Loos (Eds.), Conference Proceedings The good, the bad and the challengingThe user and the future of information and communication technologies. Koper: ABS-Center, 816-824.

8. Laugwitz B., Held T., Schrepp M. (2008). Construction and evaluation of a user experience questionnaire. In A. Holzinger (Ed.), HCI and Usability for Education and Work (USAB 2008), LNCS, 5298. Berlin, Heidelberg: Springer, 63-76.

9. Laugwitz B., Schrepp M., Held T. (2006). Konstruktion eines Fragebogens zur Messung der User Experience von Softwareprodukten (Construction of a questionnaire to measure the user experience of software products). In A.M. Heinecke, H. Paul (Eds.), Mensch und Computer im Strukturwandel. Munchen: Oldenbourg Verlag, 125 - 134. (in German)

10. Merisalu M. (2015). Professor: oppimises on olulised ka emotsioonid (Professor: Emotions are important in learning). Retrieved from $\mathrm{http}: / /$ novaator.err.ee/v/yhiskond/3d5f993d-2352-420f-8810d3cf3503c810/professor-oppimises-on-olulised-ka-emotsioonid

11. Perino O. (2017). Play, Toys and Low_Technology. The First LUDI Training School "Play and Toys for All". Heerlen, NL: Zuyd University.

12. Santoso H., Schrepp M., Isal R.Y.K., Utomo A.Y., Priyogi B. (2016). Measuring user experience of the student-centered E-learning environment. Journal of Educators Online, 13(1), 58- 79. Retrieved from http://www.ueq-online.org/wpcontent/uploads/SantosoSchreppKartonolsalUtomoPriyogi.pdf

13. Schrepp M. (2017). User Experience Questionnaire (UEQ). Retrieved from http://www.ueq-online.org/

14. Schrepp M., Hinderks A., Thomaschewski J. (2017a). Design and Evaluation of a Short Version of the User Experience Questionnaire (UEQ-S). International Journal of Interactive Multimedia and Artificial Intelligence, 4(6), 103-108. Retrieved from http://www.ijimai.org/journal/sites/default/files/files/2017/09/ijimai20174 6 14_pdf_20309.pdf

15. Schrepp M., Hinderks A., Thomaschewski J. (2017b). Construction of a Benchmark for the User Experience Questionnaire (UEQ). International Journal of Interactive Multimedia and Artificial Intelligence, 4(4), 40-44.

16. User Experience Questionnaire. (2017). (17.11.2017). Retrieved from http://www.ueq-online.org/ 